\title{
Precipitation response to extreme soil moisture conditions over the Mediterranean
}

\author{
Constantin Ardilouze ${ }^{1}$ (D) $\cdot$ Stefano Materia ${ }^{2} \cdot$ Lauriane Batté $^{2} \cdot$ Marianna Benassi $^{2} \cdot$ Chloé Prodhomme $^{1,3,4}$
}

Received: 23 July 2020 / Accepted: 30 October 2020 / Published online: 13 November 2020

(c) The Author(s) 2020

\begin{abstract}
The intimate link between soil moisture and precipitation makes it a "chicken-and-egg situation" that challenges climate studies of the continental water cycle. This association is particularly acute over the Mediterranean, increasingly exposed to droughts with climate change. This study aims at deciphering the impact of spring soil moisture state in the Mediterranean on subsequent warm season precipitation. In an idealized setup, two distinct climate models are used to generate extreme dry or wet soil conditions, and run climate simulations initialized and/or forced by these conditions. Changes in precipitation distribution and persistence are analyzed and where applicable compared to composites from a reanalysis. Spring soil moisture anomalies are found to be very persistent, but the precipitation response is largely model dependent. Overall, dry soils lead to a reduction of precipitation for early summer months and conversely for wet soils although with a fainter and less robust signal. On the other hand, wet soils tend to favor the persistence of precipitation throughout summer over several sub-regions. Our results highlight the stringent need to reduce the wide array of uncertainties associated to soil moisture, land-atmosphere coupling and convection in climate models, before ascertaining that soil moisture initialization could provide more skillful sub-seasonal to seasonal precipitation prediction.
\end{abstract}

Keywords Soil moisture $\cdot$ Precipitation $\cdot$ Mediterranean $\cdot$ Land-atmosphere coupling

\section{Introduction}

Despite large uncertainties across the globe, the Mediterranean area is one of the few where climate projections consistently foresee an increased frequency of soil moisture and precipitation droughts (Orlowsky and Seneviratne 2013). Seneviratne et al. (2013) also identify that the precipitation regime of this region is particularly sensitive to

Electronic supplementary material The online version of this article (https://doi.org/10.1007/s00382-020-05519-5) contains supplementary material, which is available to authorized users.

Constantin Ardilouze

constantin.ardilouze@meteo.fr

1 CNRM, Université de Toulouse, Météo France, CNRS, Toulouse, France

2 Fondazione Centro-Euro Mediterraneo sui Cambiamenti Climatici (CMCC), Bologna, Italy

3 Group of Meteorology, Universitat de Barcelona (UB), Barcelona, Spain

4 Barcelona Supercomputing Center (BSC), Barcelona, Spain projected changes in soil moisture at the end of the century. In present climate, results from the multi-model exercise GLACE (Global Land Atmosphere Coupling Experiment, Koster et al. 2004; Seneviratne et al. 2006) have spotted the Mediterranean as a region combining a relatively high soil moisture memory with intense land-atmosphere coupling. Given these features, seasonal prediction of precipitation over this region could theoretically benefit from an adequate soil moisture initialization, especially for summer forecasts (Materia et al. 2014). Moreover, a noticeable fraction of summer precipitation anomalies over Europe stems from spring soil moisture patterns over Eastern Europe (Yang et al. 2016), a region where spring soil moisture has a large interannual variability, although that sector encompasses only a limited fraction of the Mediterranean basin. However, unlike 2-meter temperature, the multi-system effective predictability study from Ardilouze et al. (2017) does not conclude to any particular improvement of prediction skill over the Mediterranean for summer precipitation in relation to spring soil moisture initial conditions. Conversely, at the weather time scale, Helgert and Khodayar (2020) recently demonstrated the value of a land initialization assimilating 
high resolution remotely-sensed soil moisture to forecast heavy precipitation events over Spain.

Comprehending land-precipitation feedback is challenging, because it depends on the studied location and the considered space and time scale. Although the impact of soil-moisture on precipitation is mostly local (Wei and Dirmeyer 2012), the sign and intensity of the feedback can be found contradictory between studies based on different evaluation methods. In some cases, long-lasting positive soil moisture anomalies exert a positive control on the evapotranspiration rate, which in turn increases the supply of humidity in the lower atmosphere and thus moist static energy. Consequently, local atmospheric convection and precipitation is enhanced (e.g. Schär et al. 1999; Koster et al. 2006). This positive feedback due to moisture recycling can compete with a negative feedback associated to boundary layer dynamics and mesoscale circulation prone to favor precipitation over dry (Taylor et al. 2012) and heterogeneous soils (Guillod et al. 2015). For example, the study from Tuttle and Salvucci (2016) reveals an opposite feedback sign between the West of the United States, where increased (decreased) soil moisture favors increased (decreased) precipitation, and the East where the land precipitation feedback is negative. Additionally, the contribution of soil water content to precipitation anomalies is difficult to evaluate because it is entangled with other 'non-land' contributions such as remote sea surface temperature anomalies (Orth and Seneviratne 2017) and atmospheric dynamics (Tuttle and Salvucci 2017).

A few numerical studies have addressed the precipitation response to soil moisture conditions over Europe in terms of involved physical processes (Schär et al. 1999) or variability (Ardilouze et al.2019a), but to our knowledge, a study specifically focused on the Mediterranean is still missing. Climate modelling tools are valuable allies for such investigations, since soil moisture can be specified at will. Here, we aim at understanding the extent to which precipitation characteristics respond to anomalous Mediterranean soil moisture conditions, in order to evaluate the potential for sub-seasonal to seasonal predictability originating from soil moisture initialization. With a multi-model approach, we knowingly apply extreme soil moisture perturbations in the Mediterranean region so as to maximize the precipitation response, with an endeavour to assess their realism by confronting the results to observations.

The experimental design is further detailed in Sect. 2. Then, a validation of the models against reference data is achieved in Sect. 3. Results on precipitation anomalies are analysed in Sect. 4 and those on precipitation persistence in Sect. 5. Finally, Sect. 6 provides a discussion and concluding remarks.

\section{Experimental setup}

The study aims at gaining insight on the maximum extent to which Mediterranean soil moisture can modulate precipitation. Idealized modelling experiments are well suited to this purpose since General Circulation Model (GCM) integrations can be driven with extremely dry or wet initial or boundary soil moisture conditions. Because of this idealized framework, the reference for comparison is taken from a baseline unforced simulation for each GCM. In order to maximize the atmospheric response to soil moisture forcing, all the simulations described hereafter are in AMIP-mode, meaning that the atmosphere is forced by prescribed ocean and sea-ice conditions. Details on the models and the setup of this sensitivity experiment, also used in Materia et al. (Submitted) and partly inspired from Lorenz et al. (2010), are given below.

\subsection{Contributing models and baseline reference integration}

Two GCMs have taken part in this study : CMCC-SPSv3 (Sanna et al. 2016) and CNRM-CM6-1 (Voldoire et al. 2019) with a respective horizontal resolution of about $1^{\circ}$ and $1.5^{\circ}$. A 50-year simulation is carried out for each model after a 10-year spinup, with ocean and sea-ice forcing derived from a 1981-2010 monthly climatology from the HadISST1 dataset (Rayner et al. 2003). This 30-year period corresponds to the current WMO climate standard normals. The radiative forcing, including greenhouse gases, ozone, aerosol and solar forcing, is fixed and set to year 2000. The role of this control simulation is twofold. It serves as a benchmark against which perturbed simulations are evaluated, but it also provides a set of 50 atmosphere initial conditions (one per year) to generate ensembles of perturbed simulations, as explained in Sect. 2.2. The baseline simulations are referred to as CMCC-B0 and CNRM-B0.

\subsection{Perturbed soil moisture simulations}

Two aspects are being investigated in this study: the atmospheric response to extreme soil moisture conditions in the Mediterranean imposed either as a boundary condition of the atmosphere, or as initial condition in a coupled framework, i.e. with land and atmosphere evolving interactively.

We define the MED region ( $10 \mathrm{~W}-45 \mathrm{E}, 28 \mathrm{~N}-50 \mathrm{~N})$ that covers a large fraction of the Mediterranean basin, and is depicted by a dotted purple line on the spatial maps in what follows. To produce anomalous Mediterranean soil conditions, ensemble 18-month global land-only simulations are performed with atmospheric forcing derived from 50 different years of the NOAA-20CR V2c reanalysis (Compo et al. 
2011), in which precipitation rate is changed over MED. More precisely, precipitation is entirely suppressed to provide dry land conditions, and for wet soil conditions, the precipitation forcing is amplified by adding three standard deviations computed over the 1913-2012 NOAA-20CR monthly mean precipitation to each precipitation forcing input. Outside the MED domain, the precipitation rate is not modified.

The 18-month length of land-only simulations as well as the degree of perturbation of the precipitation forcing have been chosen empirically as explained hereafter. Our goal was to obtain May 1st dry land conditions corresponding to suppressed evapotranspiration over MED, and conversely wet land conditions with evapotranspiration equalling potential evapotranspiration (i.e. soil moisture not being a limiting factor). These extreme conditions are reached when the soil wetness index (SWI) becomes negative (dry case) or exceeds 1 (wet case). This dimensionless index is defined as :

$S W I=\frac{\theta-\theta_{w}}{\theta_{f}-\theta_{w}}$

where $\theta$ is the soil water content, $\theta_{w}$ is the permanent plant wilting point and $\theta_{f}$ is the field capacity. Preliminary tests have shown that a 12-month duration of land-only simulation with perturbed precipitation was necessary to obtain such thresholds over the MED domain. These extreme May 1st land conditions are used to initialize the GCMs land scheme for all the perturbed experiments (see red arrows in Fig. 1).
The free-evolving soil moisture GCM experiments are named CMCC-W1 and CNRM-W1 (CMCC-D1 and CNRMD1) when initialized with wet (dry) soil conditions. The prescribed soil moisture GCM experiments, named CMCC-W2 and CNRM-W2 (CMCC-D2 and CNRM-D2), are initialized like their W1 and D1 counterparts, but wet (dry) soil moisture conditions are then imposed over MED throughout the integration time. These initial and prescribed GCM land conditions need to be as seamless as possible to avoid a spurious numerical shock after initialization. This is why the land boundary conditions are derived from a 6-month extension of the land-only simulations described above, in order to compute a wet and a dry daily soil moisture climatology for the period comprised between May 1st and October 31 st. More precisely, these climatologies correspond to the ensemble mean of the 50-member land-only simulations smoothed up by a time running mean filter. The full setup is

Table 1 List of experiments

\begin{tabular}{lllll}
\hline Name & Ensemble & Duration & $\begin{array}{l}\text { MED initial soil } \\
\text { moisture }\end{array}$ & $\begin{array}{l}\text { MED soil } \\
\text { moisture } \\
\text { evolution }\end{array}$ \\
\hline B0 & No & 50 years & Not applicable & Interactive \\
D1 & 50 members & 6 months & Dry & Interactive \\
D2 & 50 members & 6 months & Dry & Prescribed \\
W1 & 50 members & 6 months & Wet & Interactive \\
W2 & 50 members & 6 months & Wet & Prescribed \\
\hline
\end{tabular}

Fig. 1 Schematic design of the perturbed land experiments. See Sect. 2.2 for details

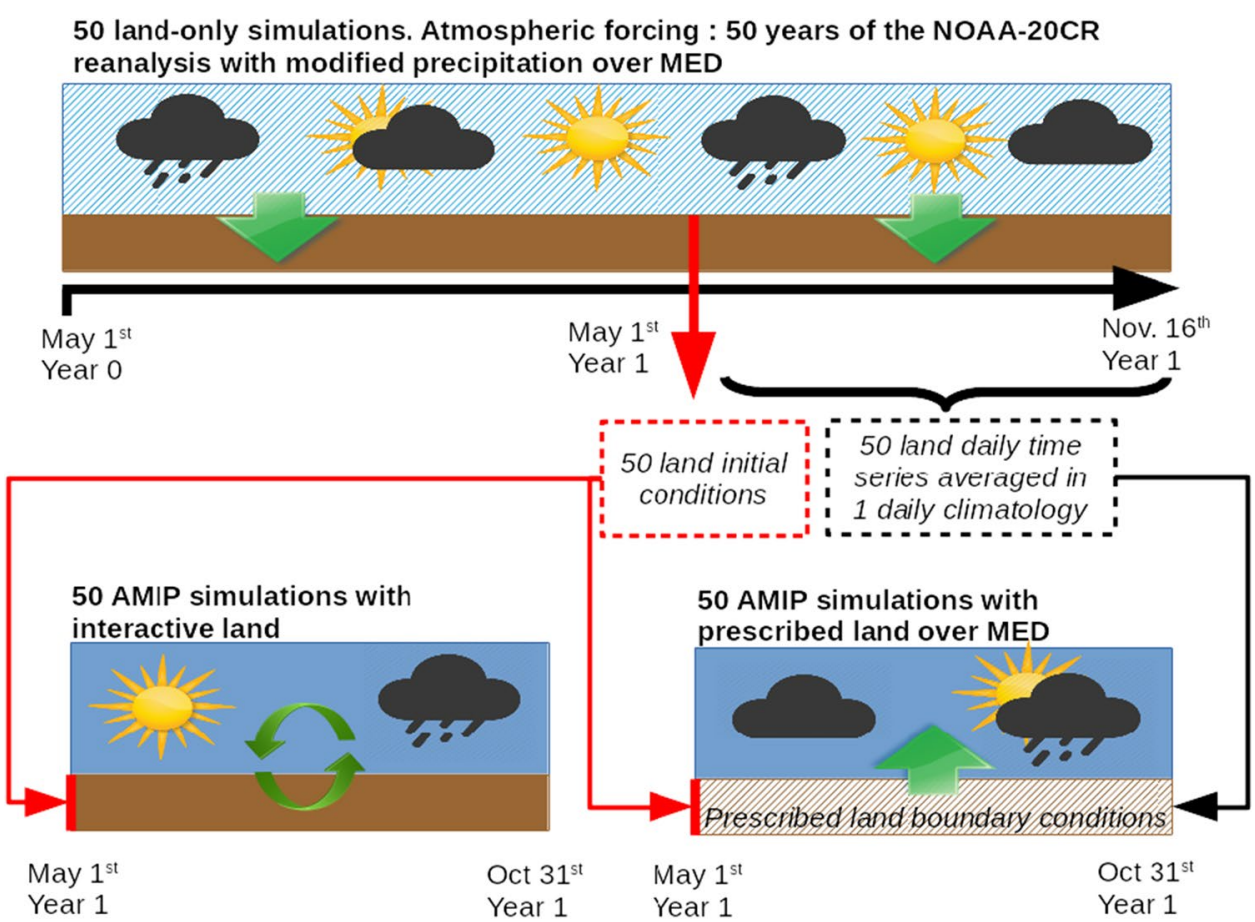


schematized in Fig. 1 and the GCM experiments are summarized in Table 1.

\subsection{Reference datasets}

The perturbed simulations D1, D2, W1 and W2 cannot be compared directly to observations nor to a reanalysis. In this idealized framework, the comparing reference for each GCM is the corresponding baseline unperturbed long simulation. Nonetheless, the use of reanalyses is relevant for the following two purposes.

Evaluation of baseline simulations A prerequisite for discussing the results from this study is that the baseline experiments simulate precipitation, soil moisture and surface fluxes realistically. We use the monthly GPCC dataset (Schneider et al. 2017, 2018) for mean precipitation and the daily MSWEP V1.2 dataset (Beck et al. 2017) for precipitation extremes in the validation section. In the absence of an absolute observation-based reference for soil moisture and surface fluxes, simulations are compared to the two centurylong reanalyses NOAA-20CR V2c and ERA-20C (Poli et al. 2016), as well as ERA5 (Hersbach et al. 2020) which is much better constrained by data assimilation than centurylong reanalyses, but available only from 1979 onward at the time of this study.

Realism of initialized simulations Despite the idealized protocol, we attempt to assess the realism of the simulations initialized with wet or dry soil conditions by means of a composite analysis based on the Mediterranean spring soil moisture state in a century reanalysis. More precisely, this composite analysis is built from the 110-year long reanalysis ERA-20C, for which years are sorted according to the value of a soil moisture index defined over the MED domain. This index corresponds to the May 1st spatially averaged water content of the top first meter of soil. The 25 years characterized by the highest (the lowest) index provide an ensemble of observed years with wet (dry) soil conditions on May 1st. The 60 remaining years of the reanalysis provide a benchmark ensemble representing average soil moisture conditions for this date. Figure 2 shows that the mean soil moisture anomalies in the resulting composites is spatially uneven, and significant anomalies are also found outside MED. These constraints, inherent to the method, must be kept in mind when comparing the composites to our simulations.

In all the anomaly maps presented in the study, the gridpoint statistical significance is assessed by a Monte Carlo approach, namely the bootstrap method, that estimates the probability density function of the ensemble-mean anomalies. Here, the probability density function is derived from 500 ensembles obtained by re-sampling with replacement
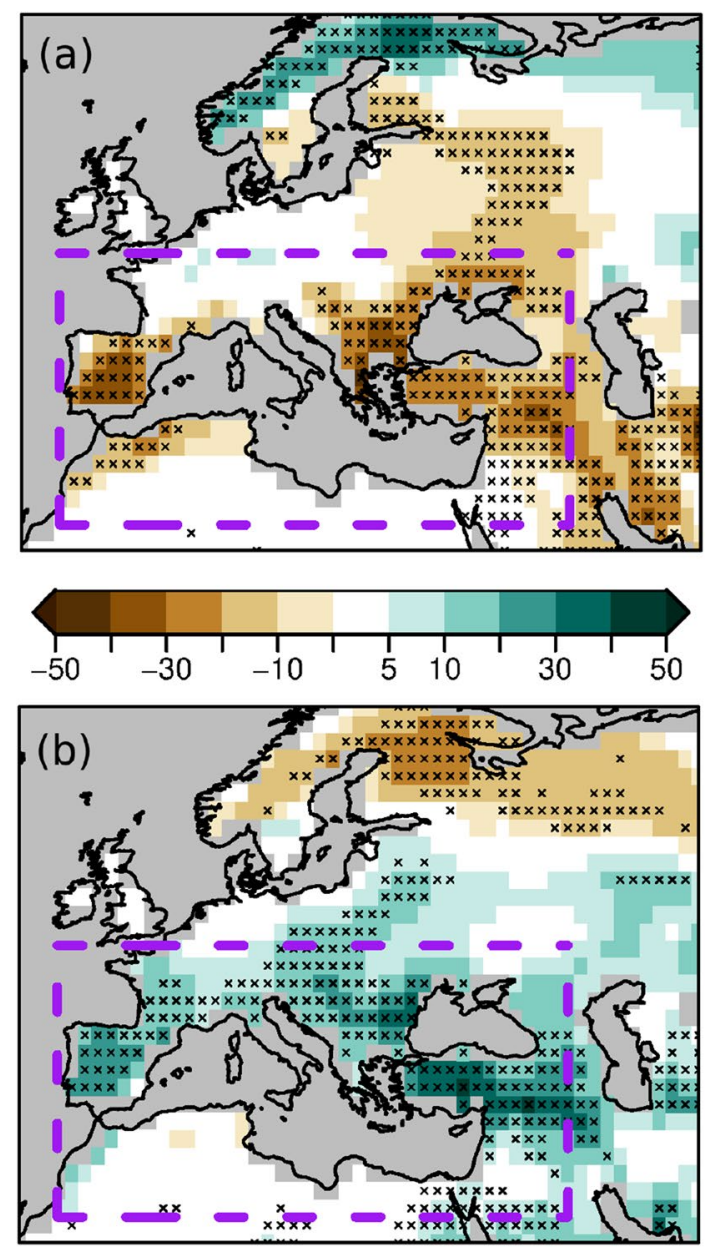

Fig. 2 Top first meter soil water content anomalies on May 1st, in kg/ $\mathrm{m}^{2}$ for dry (a) and wet (b) composites in the ERA-20C reanalysis. Stippling indicates significant anomalies at the 95\% confidence level. The MED domain is outlined by the purple dashed box

the simulated members or the reanalysis years taken into account.

\section{Validation of baseline simulations}

The GCMs used for B0 simulations have already been thoroughly evaluated in the context of international programmes such as CMIP6 (Coupled Model Intercomparison Project phase 6) or the Copernicus Climate Change Service. Here the focus is set on the most relevant fields for this study, i.e. soil moisture and precipitation.

\subsection{Seasonal cycle of soil moisture, evapotranspiration and precipitation}

Because of the lack of homogeneous gridded observations of soil moisture, we refer to two century reanalyses, i.e. 
NOAA20CR and ERA-20C. These reanalyses are not absolute reference since soil moisture is derived from model outputs without proper data assimilation; its variations are only constrained by assimilated surface pressure observations, as well as surface marine winds for ERA-20C. Consequently, air temperature and humidity deviation from observations is larger than for a reanalysis assimilating a vast amount of observed data, such as ERA5. However, due to their centurylong time span, we can subsample enough years to proceed to a fair spread comparison with the 50 years of CMCC-B0 and CNRM-B0. Here, we select the years 1961-2010 to stay as close as possible to the forcing imposed to B0 (i.e. year 2000 greenhouse gases and aerosols, 1981-2010 climatological sea surface temperature and sea-ice, see Sect. 2.1). The comparison with a shorter and different period (1979-2018) of ERA5 serves to evaluate the consequences of this tradeoff between a large sample size and a limited amount of assimilated data in the century reanalyses.

We start by evaluating soil moisture evolution and distribution, shown by a box-and-whiskers plot (Fig. 3a). This representation allows to compare at the same time the soil moisture seasonal cycle and the spread. Both remain very close for the two models (blue and green boxplots) throughout the 6 months. In the reanalyses, the interannual variability shown by the range of the black, gray and red boxplots is far more pronounced than in models, particularly during the warmest months. This lower variability in our simulations could be a consequence of identical climatological sea surface conditions prescribed for each year of the model integration, while in the reanalysis, ocean evolves freely, only constrained by data assimilation guiding its interannual variability. This hypothesis is further supported by the findings from Orth and Seneviratne (2017). As to the seasonal cycle, Mediterranean soil dries out substantially faster during the warm season in the century reanalyses, but not in ERA5 for which the dispersion is larger and encompasses that of the two models as well as the century reanalyses, despite a smaller ensemble size. Should our models overestimate the superficial soil moisture in summer, this could translate into an altered partition of energy turbulent fluxes between latent and sensible heat to balance incoming surface radiation. To verify this hypothesis, we compute the evaporative fraction $E F$, defined as:

$E F=\frac{Q_{l}}{Q_{s}+Q_{l}}$

where $Q_{l}$ is the latent heat flux and $Q_{s}$ the sensible heat flux. An excess of soil moisture available for evaporation would translate into a lower fraction of incoming solar energy converted into sensible heat flux and thus a higher $E F$. The monthly evolution of $E F$ averaged over MED land grid points substantially differs from that of soil moisture
(Fig. 3b). After a relatively good agreement in May, the decrease of $E F$ in the models is slower than the NOAA20CR reanalysis but faster than ERA-20C and especially ERA5, up to mid-summer. During early fall, $E F$ in CMCC-B0 and CNRM-B0 increases faster and ultimately reaches or exceeds that of reanalyses in October. Therefore, despite large soil moisture discrepancies between models and reanalyses, the CMCC-B0 and CNRM-B0 evaporative fraction remains consistent with century reanalyses, at least for the May-to-August period. However, it is substantially lower than ERA5 in July and August. For the evaluation of the precipitation spread (Fig. 3c), the 1961-2010 GPCC dataset is depicted by the orange box and whiskers. Since it is based on direct observations, we consider it as the best estimate of the truth in our study. Although the considered periods do not match (1979-2018 for ERA5), ERA5 precipitation shows a positive bias with respect to GPCC, which could explain the high $E F$ values in mid-summer. When considering a common period (i.e. 1979-2016), this positive bias may be appreciated also in the spatial distribution of precipitation (Supplementary figure S1 (g-i)). If we now set aside ERA5 and focus on the two models and the two century reanalyses, we can notice that:

- the differences in precipitation spread do not explain directly those in $E F$, and even less those in soil moisture. Reasons for soil moisture and $E F$ discrepancies could therefore arise from other terms involved in the surface water budget (wind and air temperature driving the evaporative demand and incoming surface radiation) and/or inter-model differences in the surface resistance to evaporation (Lehmann et al. 2018).

- CMCC-B0 pan-Mediterranean precipitation is close to GPCC in May and early fall, but too scarce during the warmest months. Conversely, CNRM-B0 rainfall is fairly good during mid-summer months but excessive in late spring and October. The spatial patterns of precipitation biases are thus analyzed in the next subsection.

\subsection{Mean precipitation bias}

To evaluate the precipitation bias, we now refer to a monthly climatology of the GPCC dataset. This climatology is computed over the 1961-2010 period for which we assume a limited precipitation trend associated to climate warming (Orth et al. 2016), necessary for a fair comparison with B0 simulations forced by year 2000 greenhouse gases. For the sake of clarity and consistency with results commented further in Sect. 4, we focus here on bi-monthly biases, namely May-June, July-August and September-October. Over MED, both models show a persisting negative precipitation bias, stretching from the Balkans eastward to the Russian Caucasus (Fig. 4A). Dry biases tend to be more severe and 
Fig. 3 Monthly spread of a the top first meter soil water content averaged over MED, in $\%$ of the May median value, b the evaporative fraction over land and $\mathbf{c}$ the precipitation rate over land in $\mathrm{mm} /$ day based on 50 years (namely $1961-2010$ for ERA20C, NOAA20CR and GPCC) or 40 years for ERA5 (1979-2018)

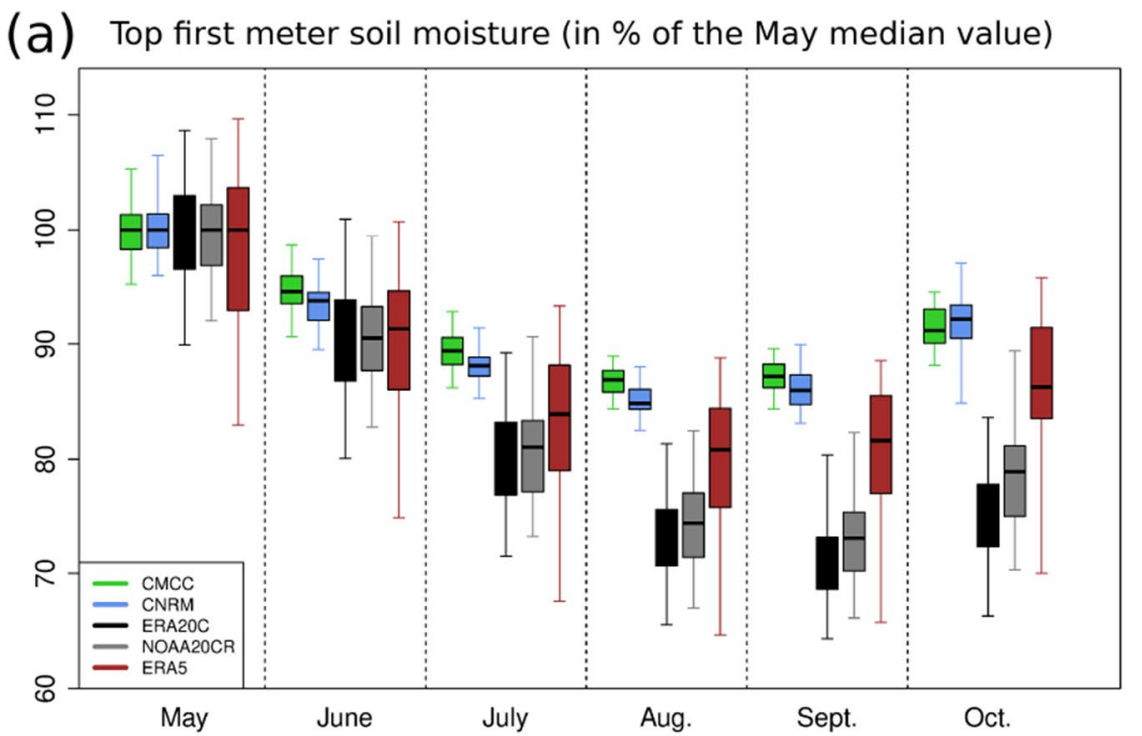

(b)

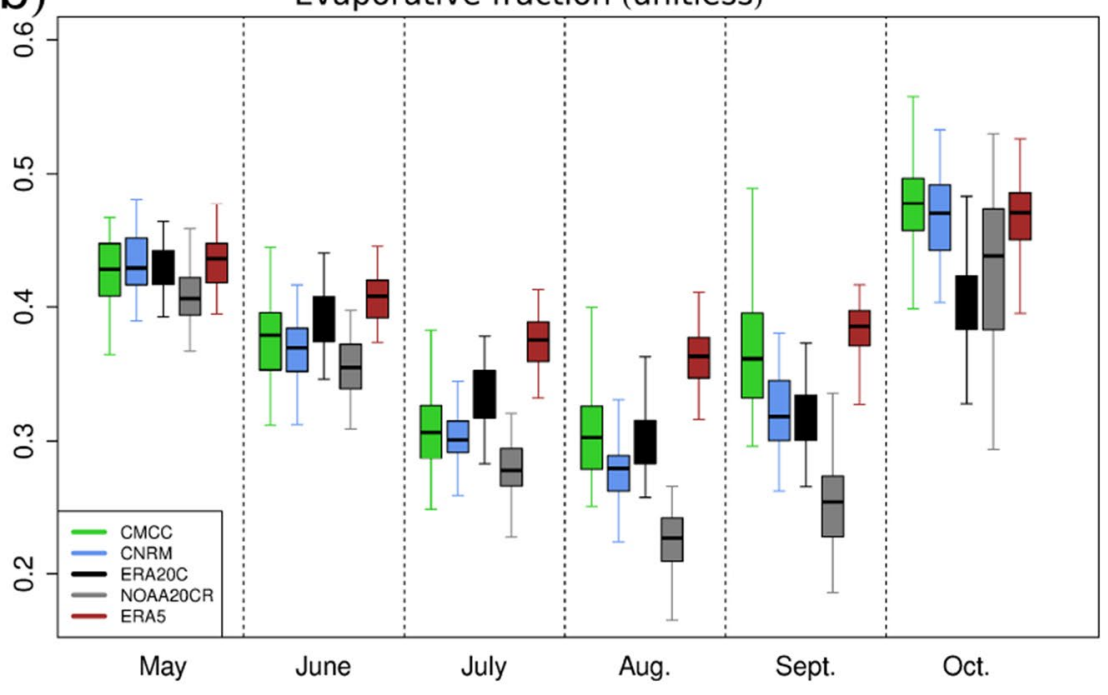

(C)

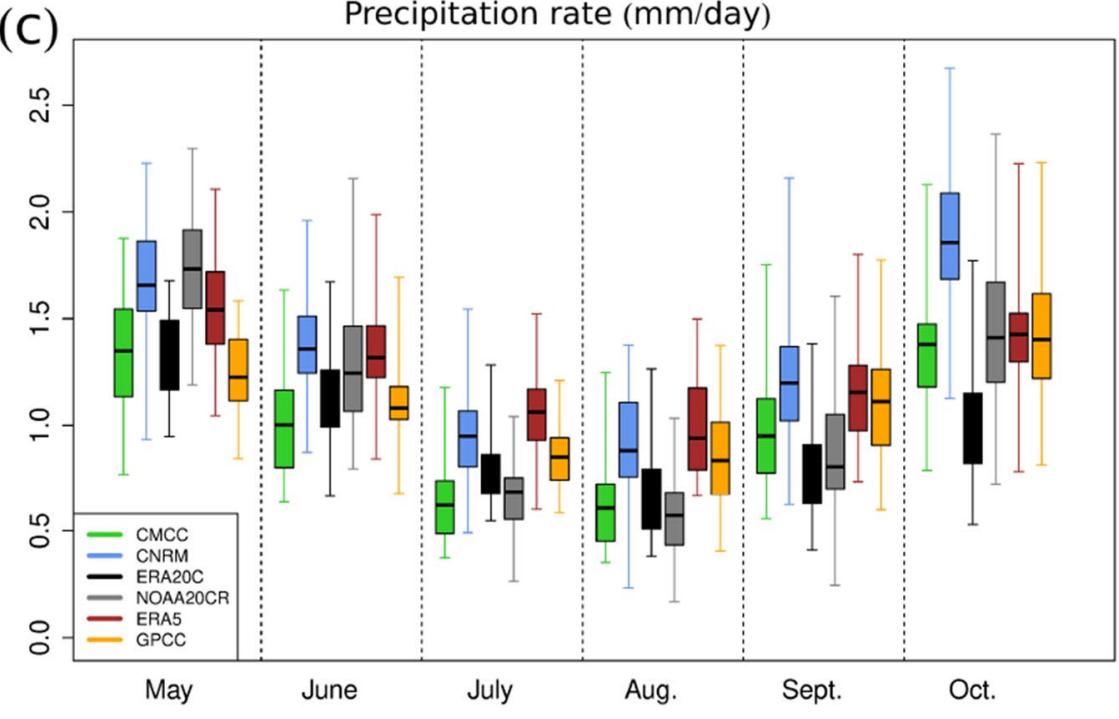


(a) CMCC May-June

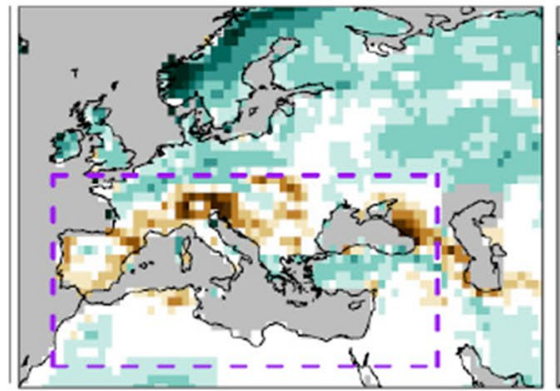

(d) CNRM May-June

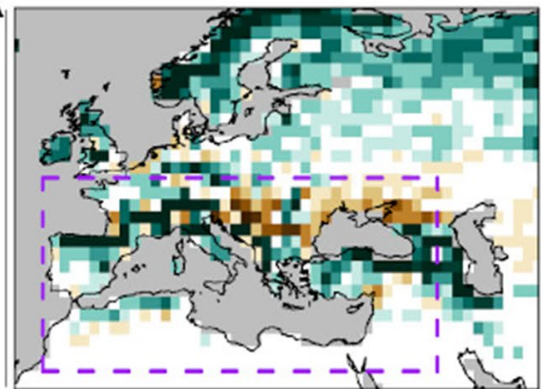

(b) CMCC July-Aug.

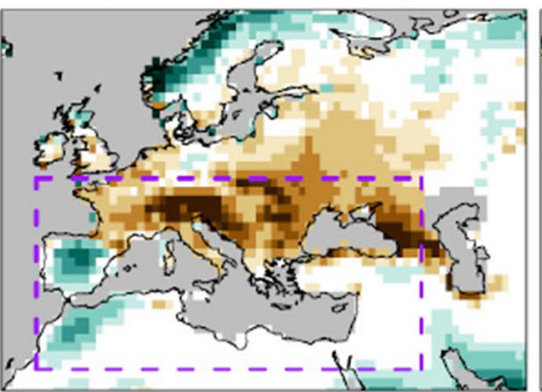

(e) CNRM July-Aug.

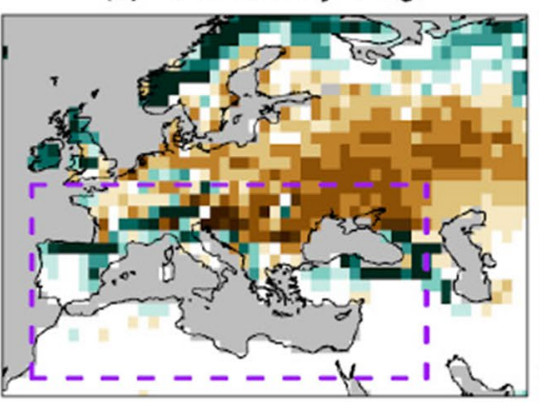

(c) CMCC Sept.-Oct.

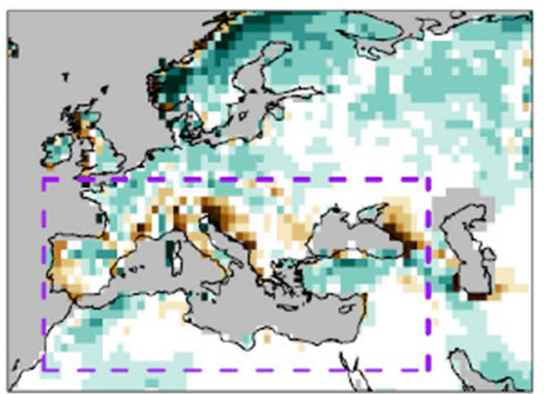

(f) CNRM Sept.-Oct.

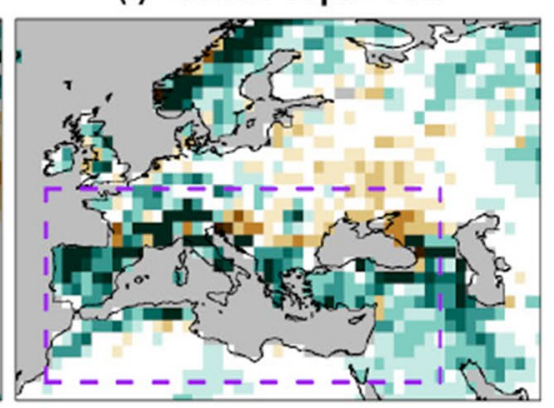

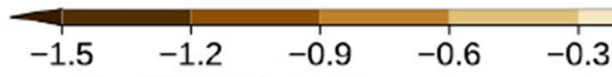

(a) CMCC May-June

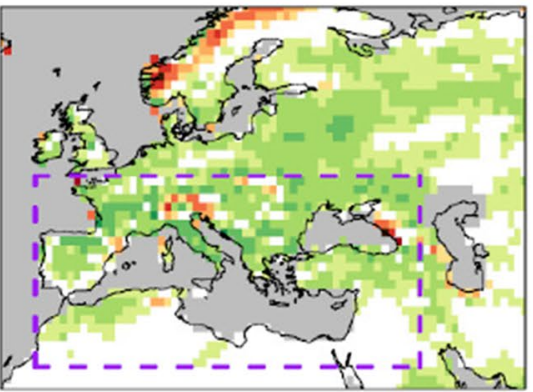

\section{(d) CNRM May-June}

(b) CMCC July-Aug.

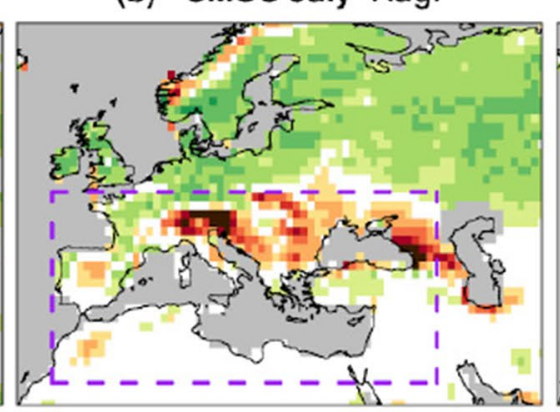

(e) CNRM July-Aug.

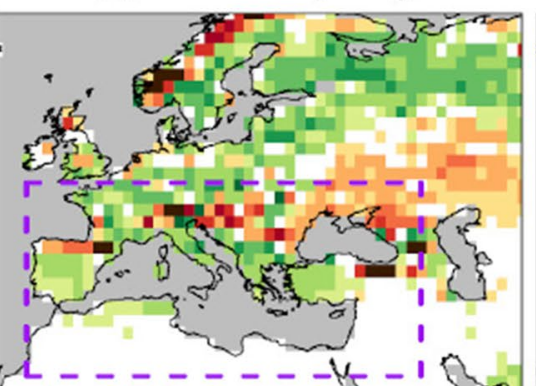

0.6

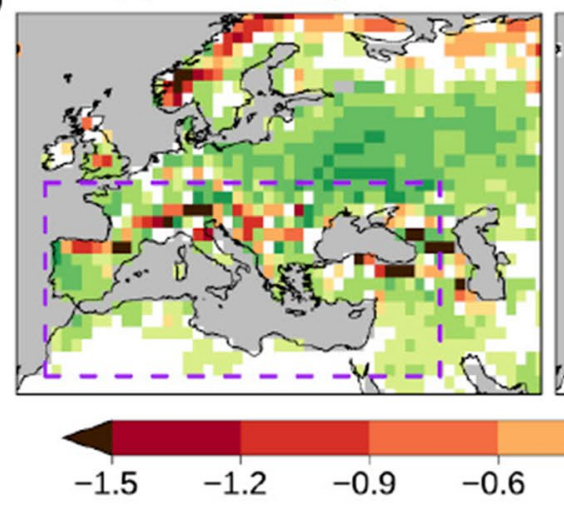

B

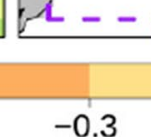

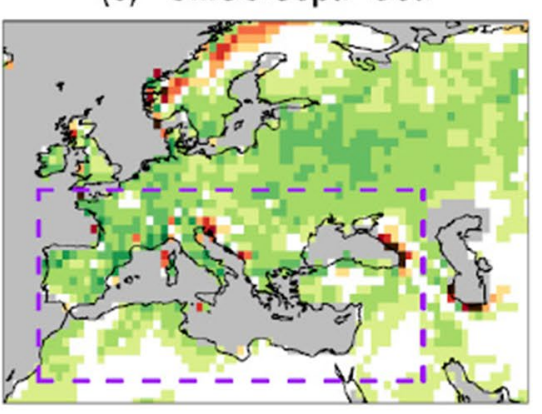

(f) CNRM Sept.-Oct.

Fig. 4 A Two-month precipitation bias against GPCC (1961-2010), in mm/day and B difference between bi-monthly model precipitation standard deviation and absolute value of the precipitation bias against GPCC (1961-2010), in mm/day

widespread in July-August. Nonetheless, throughout the sixmonth period, the CNRM-B0 precipitation bias is markedly wet over mountain ranges (Northern Spain, the Alps and southern Caucasus) while in CMCC-B0, the bias is smaller and predominantly dry, with a maximum amplitude over the Alps and Caucasus.

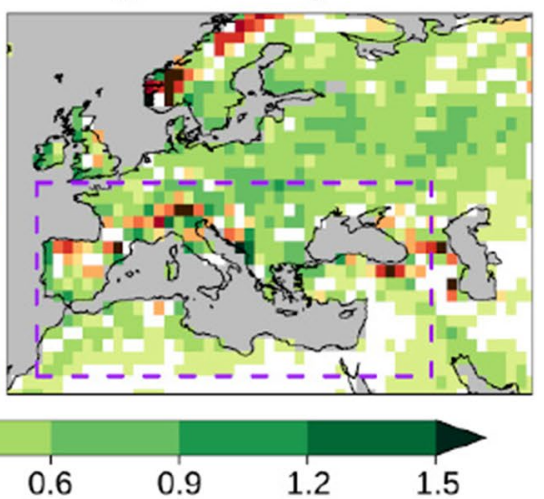


We now compare the biases magnitude with the model internal variability assessed by the bi-monthly precipitation standard deviation. Red shades in Fig. 4B indicate where the precipitation bias absolute value exceeds the model standard deviation. Regardless of the sign of the bias, this map highlights the regions where the simulated precipitation is the most inadequate relatively to the model precipitation variability. For example, despite multiple patches of positive and negative bias patterns for CMCC-B0 in May-June across Europe (Fig. 4A (a)), only those affecting Norway, the Alps and the Russian Caucasus can be considered severe from this perspective (Fig. 4B (a)).

Overall, the two models simulate fairly and comparably well the mean May-to-October precipitation over MED (not shown) notwithstanding local deficiencies, but the differences in bias patterns justify a posteriori the use of two distinct models for this study.

\subsection{Extreme precipitation bias}

We now compare the distribution of daily precipitation to evaluate how models represent extreme rainfall. We refer this time to the MSWEP v1.2 daily dataset, using the full available period, namely $1979-2015$, because the longer the period, the better defined the upper tail of the observed daily precipitation distribution and also because the B0 simulations comprise 50 years. The quantile-quantile plot (Fig. 5) compares the distribution of daily precipitation to observations over MED for the two models, upscaled to the resolution of observations.

The bisecting line corresponds to a perfect match between observations and models quantiles. Even if

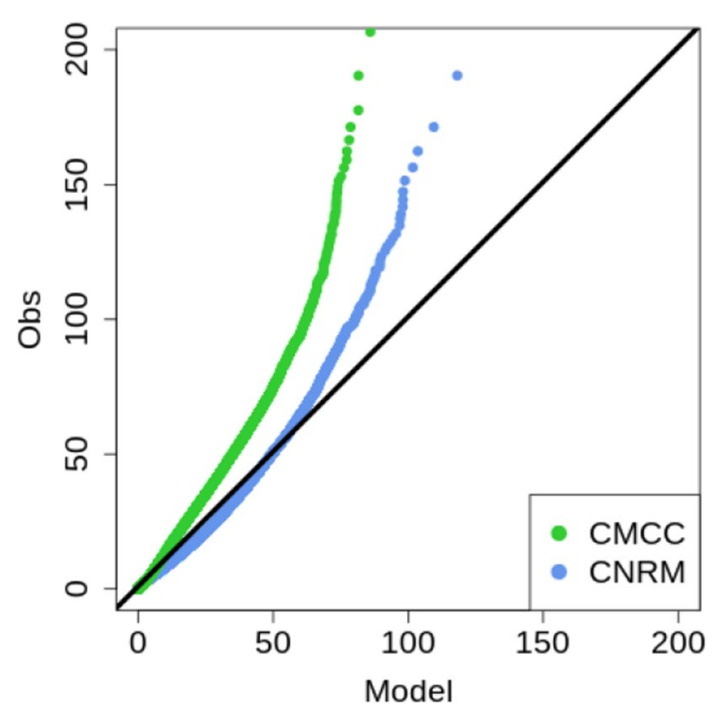

Fig. 5 Quantile-quantile comparison of observed (1979-2015) against simulated May-to-October daily precipitation over MED, in $\mathrm{mm} /$ day
CNRM-B0 better compares to observations up to $60 \mathrm{~mm} /$ day, both models strongly underestimate the upper tail of the precipitation distribution. This was expected since cloud-resolving regional climate models are required to adequately represent extreme Mediterranean precipitation (Fumière et al. 2019). The framework of this study is thus not the best suited to evaluate impact of soil moisture on precipitation extremes. Furthermore, the two models show a very limited response to either wet or dry initial soil conditions on extreme precipitation values (not shown). In the following sections, we will therefore focus primarily on how soil moisture impacts the precipitation mean anomalies and the temporal persistence of precipitation.

\section{Impact of soil moisture on precipitation anomalies}

\subsection{Soil moisture anomalies}

As stated in the introduction, soil moisture persistence is a key ingredient of the water cycle over the Mediterranean, through its impact on evaporative fraction. By design, D1 and W1 experiments are initialized with extreme soil moisture conditions. In this section, we assess the degree of persistence of these soil moisture anomalies according to their sign (positive or negative anomalies) in each model as well as in the ERA-20c-based composites. Figure 6 shows the temporal evolution of the top first meter soil water content, averaged over the full MED domain. This 1-meter depth is a common output of the GCMs and reanalyses. Additionally, it is a fair estimate of the root zone depth upper boundary in this region (Yang et al. 2016). Throughout the six months, soil moisture from D1 and $\mathrm{W} 1$ tends to get closer to B0 soil moisture without ever reaching it, meaning that our models retain considerable memory of the soil moisture initial anomaly during the full time period. It is noticeable that both models show an opposite asymmetry regarding dry and wet anomalies, the wet having a larger initial amplitude and persistence for CMCC, and conversely for CNRM. This may be explained by the differences in land surface schemes embedded into the GCMs, which also reflect on the soil water content range, very different between the two models (not shown). In the ERA-20C composites, the amplitude of early-May anomalies is smaller, which is not surprising because composite anomalies result from averaging different years with heterogeneous soil moisture in amplitude and location (Fig. 2), as opposed to the idealized protocol applied to D1 and W1 with homogeneous soil moisture anomalies across MED. We also notice that the drying stage of the seasonal cycle is steeper, whatever the initial conditions, 


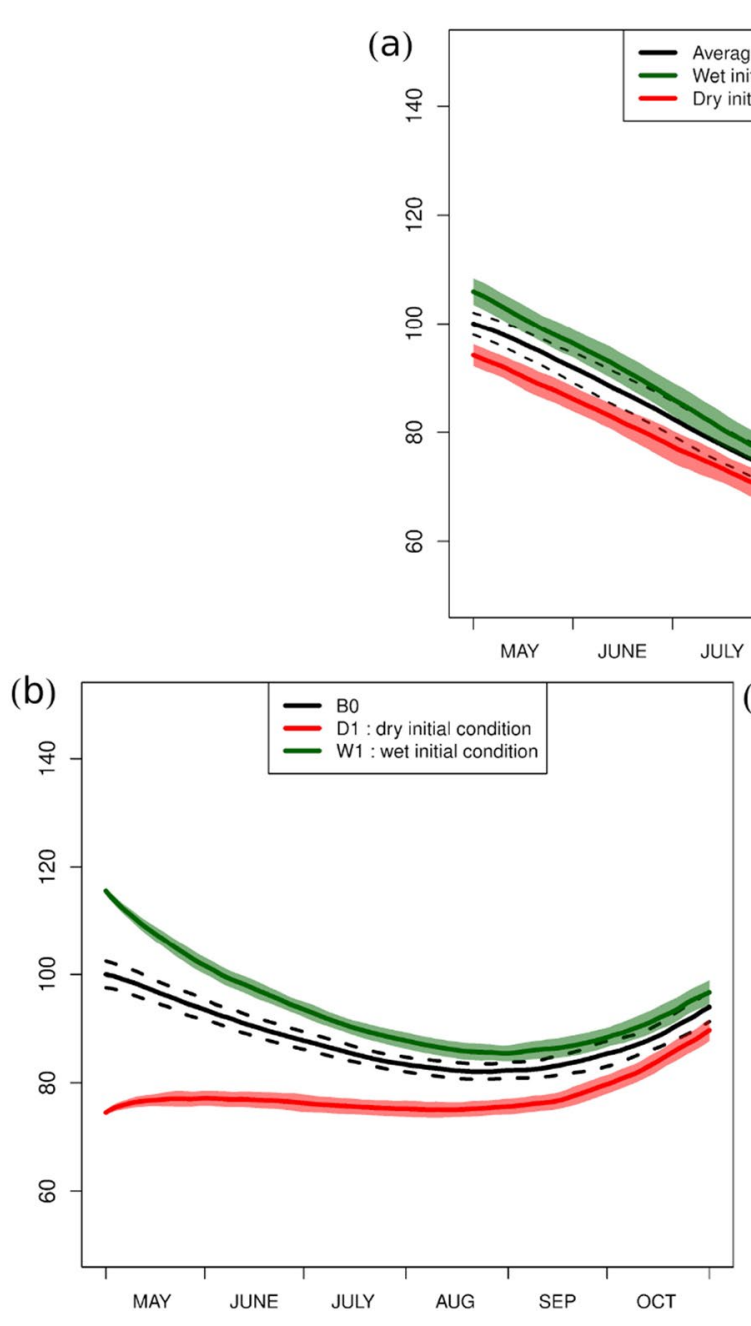

Fig. 6 Top first meter soil moisture evolution over MED with initial wet (green), dry (red) and average (black) conditions, based on ensembles from the ERA-20C composites analysis (a) and CNRM (b) and CMCC (c) simulations, in \% of the average ensemble mean

with soil moisture reaching a minimum at $70 \%$ of the May 1 st value. This result, albeit consistent with the soil moisture assessment of Sect. 3, is not necessarily close to the truth since the water budget of the reanalysis is potentially imbalanced due to data assimilation (e.g. Hersbach et al. 2020). Notwithstanding this limitation, wet and dry early May anomalies do persist until the end of October in the reanalysis, thereby supporting the results of the idealized experiments.

\subsection{Anomalies and distribution}

The impact of early May soil moisture conditions on subsequent precipitation anomalies is now analyzed by splitting the May-to-October semester into three two-month sub-periods, as in the bias analysis discussed earlier. The May-June (MJ) period is close to initialization and these

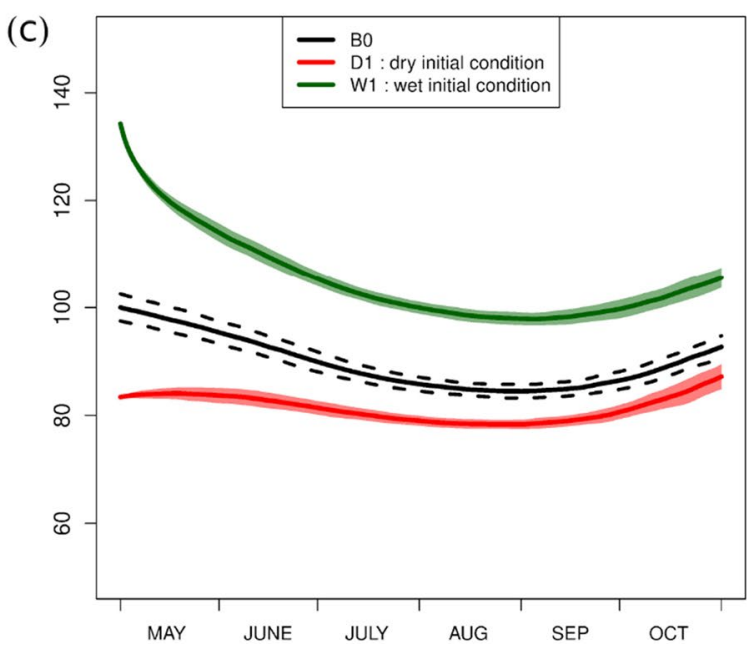

May 1st soil moisture. The ensemble means (solid lines) are framed by one standard deviation spread (colored envelopes and dashed black lines)

first two months encompass the typical sub-seasonal prediction horizon. The July-August (JA) period gathers two climatologically homogeneous months representative of the peak of the warm season. They also belong to the typical seasonal prediction horizon. Finally, the September-October (SO) period, although distant in time from early May, corresponds to the emergence of Mediterranean heavy rainfall events.

After anomalously dry soils in spring (Fig. 7), the composite years as well as the D1 experiments display a deficit of precipitation for the three sub-periods, although with various patterns and amplitude. For MJ in particular (Fig. 7a, $\mathrm{d}, \mathrm{g}$ ), the precipitation decrease concerns mainly the Balkans and northern Turkey in the composite, and appears more widespread over MED for CNRM-D1. It is weaker for CMCC-D1, but extends well north of the MED boundaries, from the Black Sea to North-West Russia. The dry anomalies 

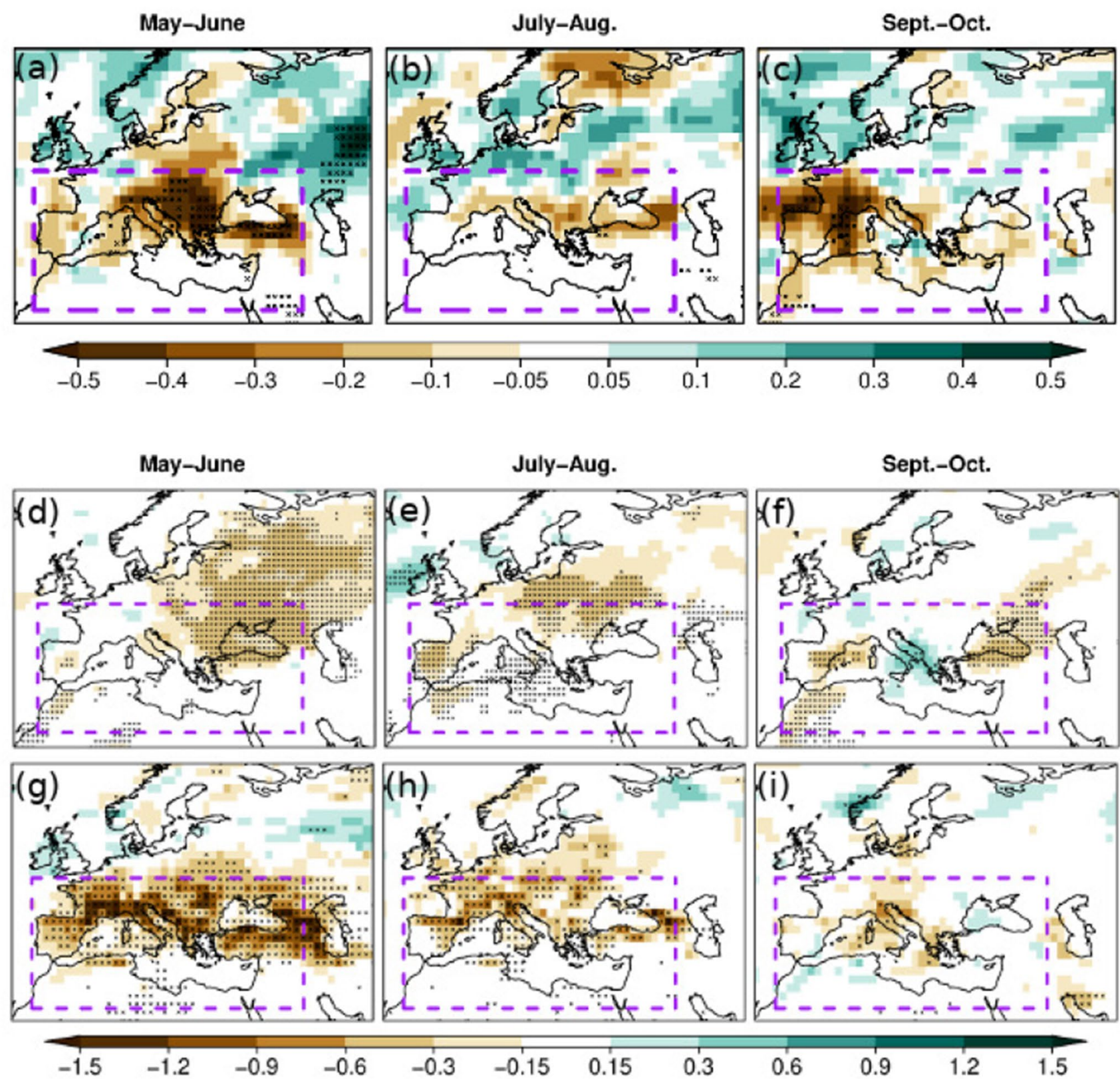

Fig. 7 2-month precipitation anomaly in $\mathrm{mm}$ /day in dry ERA20C composites (a-c), CMCC-D1 (d-f) and CNRM-D1 (g-i) for May-June (left-hand column), July-August (middle column) and

tend to decay afterwards in the composite analysis, but with remnant significant patterns in both experiments in JA. The picture is somewhat different for wet soils (Fig. 8), resulting in barely significant precipitation anomalies in the composites for the three sub-periods (note the change of color scale). The two models, however, respond fairly consistently with a positive precipitation anomaly in MJ, also present in $\mathrm{JA}$, although less pronounced. The location of these anomalies within MED differ so that we cannot conclude on a specific hotspot where spring soil moisture crucially impacts
October-September (right-hand column). The color intervals differ between composites and model results.Stippled anomalies are statistically significant at the $95 \%$ level

subsequent precipitation. Nonetheless, our results confirm that early May dry (resp. wet) soils lead to a decrease (resp. increase) of early summer precipitation over MED at least at the subseasonal timescale, and possibly beyond, up to July-August.

The contribution of atmospheric circulation to precipitation anomalies has been evaluated primarily by means of $500 \mathrm{hPa}$ geopotential height patterns in the perturbed experiments (Supplementary figure S2). In the CMCC-SPS model, W1 experiments depict a vast May-to-October geopotential 

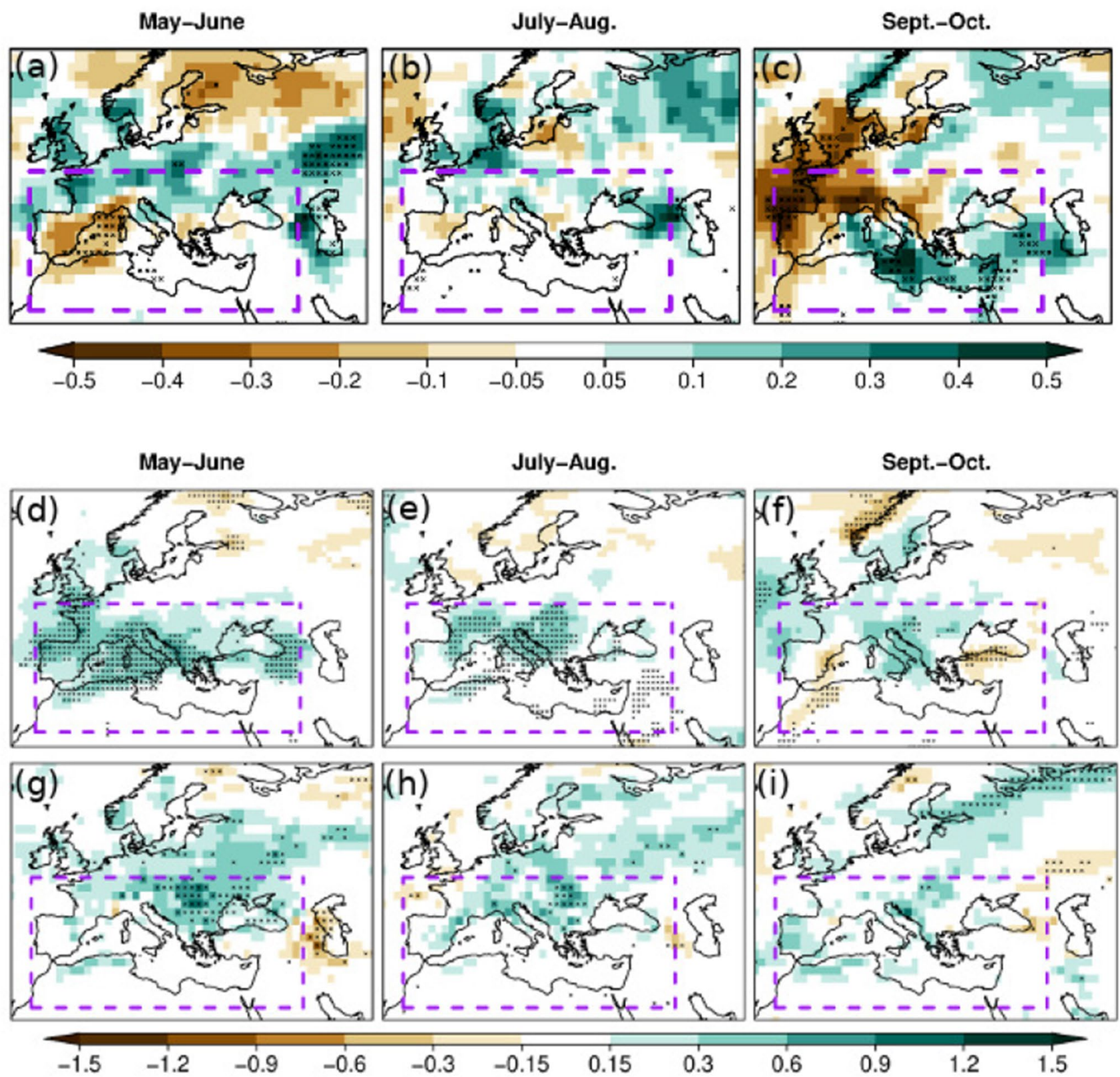

Fig. 8 Same as 7 for wet composites, CMCC-W1 and CNRM-W1

height negative anomaly over MED, and a smaller sized positive anomaly near the Black Sea in D1. This result is relatively consistent with the patterns of precipitation anomalies, and tends to support the hypothesis that soil moisture in spring can impact the warm season atmospheric circulation. A similar conclusion also applies to CNRM-D1, showing a high geopotential anomaly centered on the western Mediterranean and consistent with the precipitation anomaly pattern (Fig. $7 \mathrm{~g}-\mathrm{i}$ ). However this result is not confirmed by CNRM-W1, nor the composite analysis, and could thus be an artefact. Furthermore, geopotential height anomalies can trigger precipitations over regions distinct from where the anomalies are centered, thereby limiting the relevance of this approach. Overall, our experiments do not provide very robust conclusions on this particular aspect.

Precipitation anomalies for prescribed soil moisture experiments D2 and W2 are reported in the supplementary figure $\mathrm{S} 3$. The wet (dry) experiments show a relatively consistent response between the models with widespread enhanced (reduced) precipitation over the entire MED domain. Like for D1 experiments, the CNRM precipitation response is stronger than the $\mathrm{CMCC}$ in the case of dry soils. This could relate to the fact the CNRM land surface conditions are dryer than the CMCC counterpart and therefore 
less soil moisture is available for evapotranspiration. These precipitation responses cannot be compared to precipitation anomaly from composites selected upon a criterion of wet or dry soils over MED because in the reanalysis, precipitation anomalies are both a cause and a consequence of soil moisture anomalies. This two-way feedback loop is no longer allowed in the D2 and W2 experiments, where precipitation can be modulated by prescribed soil moisture conditions but not reversely. However, comparing them with D1 and W1 can help verify if the coupling between precipitation and soil moisture contributes to precipitation recycling and persistence.

\section{Impact of soil moisture on precipitation persistence}

\subsection{Persistence duration}

We evaluate the persistence of precipitation by means of a decorrelation function. Because small scale precipitation is noisy by nature, we apply this function to 30-day running mean precipitation spatially averaged over MED (Fig. 9). More specifically, the function consists in computing the correlation of 200 non-overlapping precipitation objects (i.e. centered on the four dates May 15, June 14, July 14 and August 13 for each of the fifty members) with the same objects lagged in time, up to 60 days.

Overall, the experiments and composite analysis show that dry initial conditions lead to a steeper decorrelation function. Furthermore, the precipitation autocorrelation after wet initial conditions lasts longer, except for CMCC-W2. With the CNRM-CM model, the correlation decay is faster

(a)

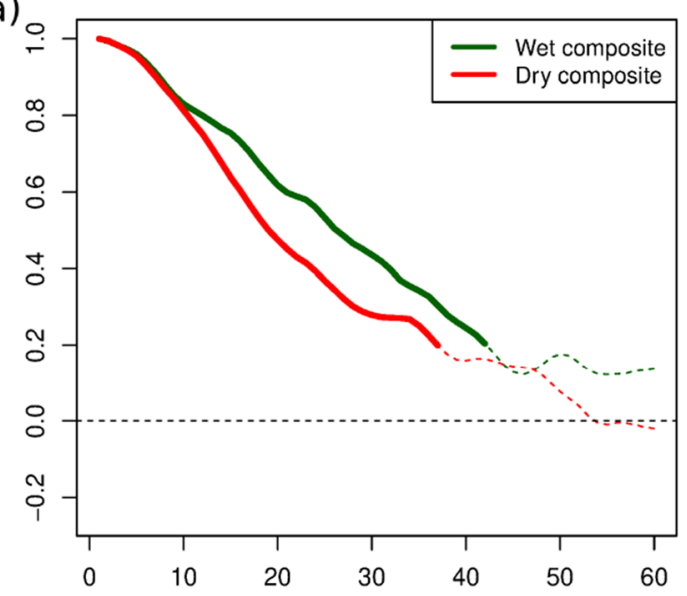

(b)

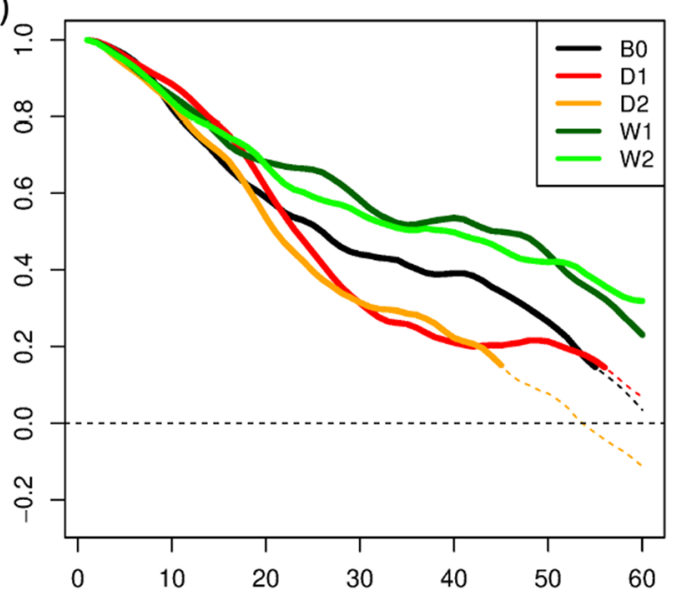

(c)

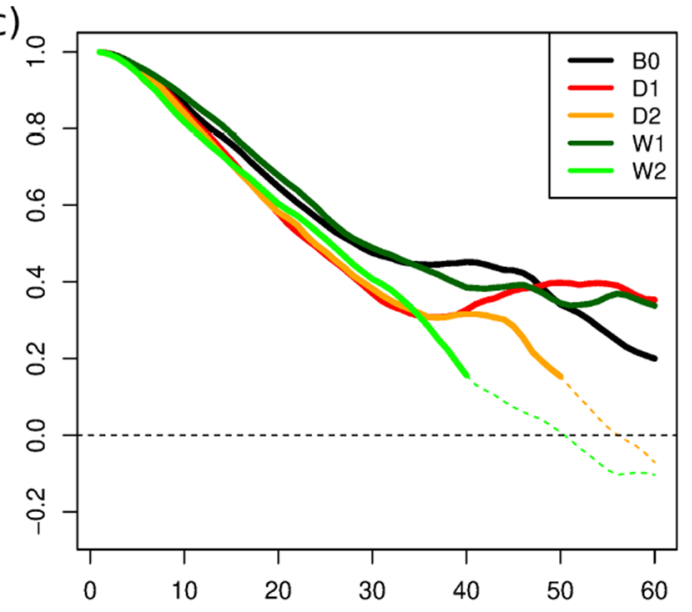

Fig. 9 30-day running mean precipitation auto-correlation decay with lag time (in days, see text for details) for composites (a), CNRM (b) and CMCC (c) experiments. Thick solid lines indicate significant correlation at the $95 \%$ level 
for dry simulations D1 and D2 than for the wet counterparts, B0 staying in between. However, little difference is found between coupled and uncoupled simulations, except beyond 45 days where D2 precipitation decorrelates faster than D1. The CMCC experiments tell a different story. The correlation decay in the uncoupled W2 simulation is comparable to that of the dry D1 and D2 simulations. On the other hand, the coupled counterpart W1 decorrelates slower beyond 30 days. When comparing D1 and D2, we can also notice that D1 correlation drops as fast as D2 up to 40 days but remains significant afterwards. In this model, the land-atmosphere coupling contributes more obviously to precipitation persistence over MED.

This analysis based on decorrelation time suggests that even if the effect of the spring soil water content (i.e. dry or wet) predominates for precipitation persistence considering the full MED domain, the contribution of the landatmosphere coupling is not off the table. The following section proposes to examine this contribution at the local scale.

\subsection{Persistence location}

The precipitation persistence is not expected to be homogeneous across MED. The decorrelation functions presented above conceal the spatial patterns of this persistence. Hence, we performed a pointwise 30-day lagged autocorrelation applied to a 30-day mean precipitation. The lag is knowingly identical to the precipitation averaging time slot in order to avoid any overlap prone to hamper the interpretation. Figure 10 illustrates the 30-day lag precipitation persistence in the case of wet soils.

In the composite analysis, persistence is rather marked, with a few regions standing out such as the Caucasus, the Balkan peninsula, the Atlas mountains and to a lesser extent Turkey, North Italy, Iberia and Tunisia. Conversely to the decorrelation lag time study, autocorrelation patterns are weaker in the experiments than in the composite. Both models reveal a slightly weaker persistence over Europe for W2 than for W1, although not on the same regions. For example, the Balkans and the Caucasus stand out in the CMCC model, but not Iberia, which shows more persistence in the CNRM model. In the latter, the Atlas is more prone to precipitation persistence in the case of wet soil forcing (W2). However, at the pan-Mediterranean scale, spatially averaged autocorrelations (not shown) do not differ significantly between coupled and uncoupled simulations. Because of very similar results and for the sake of clarity, precipitation autocorrelation maps for the 'dry' experiments can be found in the supplementary figure S4. As expected from the previous section, the autocorrelation is weaker in general in the models as well as in the ERA-20C composite with respect to the 'wet' counterparts. However, the regions with the strongest precipitation persistence appear relatively consistent in the 'wet' and 'dry' cases. This visual similarity is quantified by means of the spatial correlation of the persistence patterns over MED (Table 2). The relatively high correlations found, all significant at the $95 \%$ confidence level, confirm a substantial degree of resemblance of these patterns, even more pronounced in the ERA-20C composite.

To sum up, wet soils in early May lead to more persistent precipitation over MED, but the coupling between land and atmosphere seems to contribute only marginally to this persistence whatever the soil moisture state in spring. However, the many differences between the composite analysis and the two different models also shed light on the uncertainties and the complexity of the processes at stake when it comes to land-atmosphere interactions.

\section{Discussion and conclusion}

Soil moisture and precipitation are intimately linked components of the climate system. Based on a set of idealized numerical experiments, our study aimed at exploring the extent to which spring soil moisture can affect several aspects of the subsequent precipitation over the Mediterranean. The multi-model approach was supported by a composite analysis of a century-long reanalysis. The main conclusions drawn from the study are the following.

1. Mediterranean soil moisture anomalies in early May can persist at least until late October.

1. Dry spring soil moisture lead to reduced precipitation during early summer months, mainly over the Balkans. Wet soil moisture impact is more uncertain, despite a good agreement between models for a positive and longlasting precipitation anomaly over this region.

2. On average, precipitation shows more persistence in response to wet soils in spring than to dry soils. The land-atmosphere coupling seems to contribute to the precipitation persistence over several regions, although these regions are quite model-dependant and no robust signal emerges at the pan-Mediterranean scale.

Notwithstanding these findings, our study points out a very large spectrum of uncertainties. First, although the comparison of numerical experiments with composites seems appropriate here, it is not absolutely fair, because the members of the simulated ensembles have spatially homogeneous soil moisture anomalies and climatological sea-surface temperature, unlike the ERA-20C composite members. This homogeneity may also alter the precipitation response associated to spatial soil moisture 
Fig. 10 30-day ensemble mean precipitation lagged autocorrelation (see text for details) for wet composites analysis (a), CMCC-W1 (b) CMCC-W2 (c), CNRM-W1 (d) and CNRMW2 (e). Stippling indicates significant correlations at the 95\% level
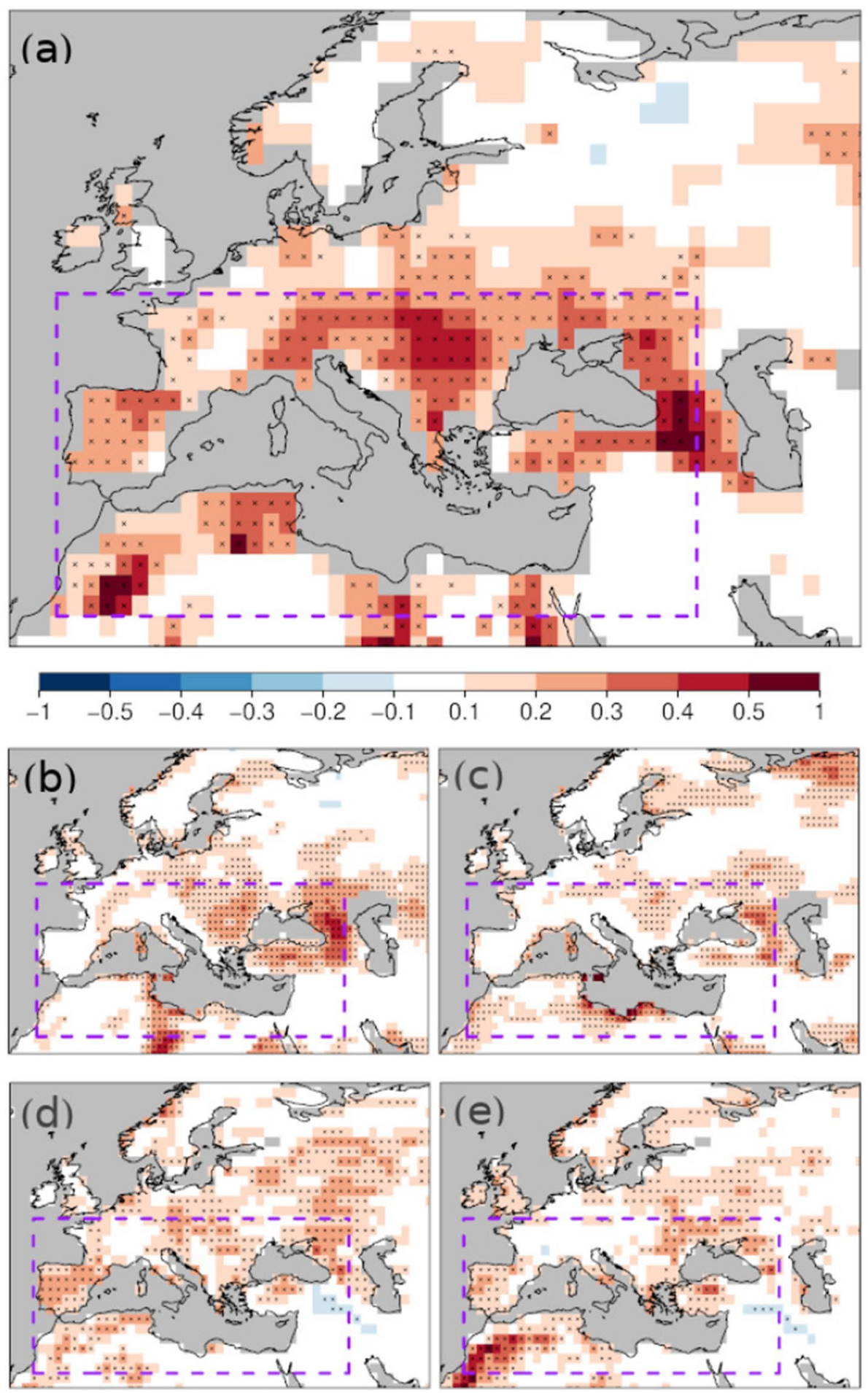

Table 2 Spatial correlation between precipitation auto-correlation patterns over MED

\begin{tabular}{llr}
\hline Dry vs. wet composite & CMCC D1 vs. W1 & CMCC D2 vs. W2 \\
\hline 0.71 & 0.48 & 0.51 \\
\hline & CNRM D1 vs. W1 & CNRM D2 vs. W2 \\
\hline
\end{tabular}


heterogeneities, originating from convection and mesoscale circulation according to several studies (Taylor et al. 2012; Guillod et al. 2015; Imamovic et al. 2017). Furthermore, the limited length of the reanalysis constrains the composite size and the amplitude of their soil moisture anomalies. Discrepancies between land surface models, including that used to produce the reanalysis, also hamper the confidence in some results (Knist et al. 2017). For example, the assessment of the coupling between soil moisture and evapotranspiration (not shown) reveals some discordance, thereby implying that the models responses to perturbed soil moisture translate into diverse precipitation anomalies. For that matter, confronting our results to comparable experiments based on high resolution regional climate models capable of resolving local circulation induced by soil moisture small scale patterns could be insightful.

Overcoming the above-mentioned uncertainties is a long-term process, that will require continued and coordinated research efforts at every step of the water cycle from land surface schemes and water exchange at the land-atmosphere interface up to boundary layer and moist convection physics. Ongoing international initiatives such as the Land Surface, Snow and Soil moisture Model Intercomparison Project (LS3MIP, Van den Hurk et al. 2016) and the Local land-atmosphere Coupling perspective (LoCo, Santanello et al. 2018) are paving the way for a better comprehension and more realistic representation of soil moisture-precipitation feedback. They will ultimately help mitigating the model biases that are suspected to alter the skill of sub-seasonal to seasonal predictions conveyed by soil moisture anomalies (Ardilouze et al. 2019b).

In the meantime, studies based on a simple water balance model similar to that of Koster et al. (2020) applied to subseasonal precipitation prediction instead of temperature could also help quantifying the amount and location of the predictive potential stemming specifically from soil moisture initialization. Finally, a renewed coordinated multi-model exercise inspired from GLACE2 but with a unified strategy for land initialization, would be worth fostering to re-assess the soil-moisture induced climate predictability in the light of the modelling improvements achieved since the first initiative launched in the early 2000 's.

Acknowledgements This work is a contribution to the HyMeX program through the project ERA4CS-MEDSCOPE, co-funded by the Horizon 2020 Framework Program of the European Union (Grant agreement 690462). Support for the Twentieth Century Reanalysis Project version $2 \mathrm{c}$ dataset is provided by the US Department of Energy, Office of Science Biological and Environmental Research (BER), and by the National Oceanic and Atmospheric Administration Climate Program Office. Chloé Prodhomme was supported by the Spanish Juan de la Cierva (IJCI-2016-30802) program.

Open Access This article is licensed under a Creative Commons Attribution 4.0 International License, which permits use, sharing, adaptation, distribution and reproduction in any medium or format, as long as you give appropriate credit to the original author(s) and the source, provide a link to the Creative Commons licence, and indicate if changes were made. The images or other third party material in this article are included in the article's Creative Commons licence, unless indicated otherwise in a credit line to the material. If material is not included in the article's Creative Commons licence and your intended use is not permitted by statutory regulation or exceeds the permitted use, you will need to obtain permission directly from the copyright holder. To view a copy of this licence, visit http://creativecommons .org/licenses/by/4.0/.

\section{References}

Ardilouze C, Batté L, Bunzel F, Decremer D, Déqué M, Doblas-Reyes F, Douville H, Fereday D, Guemas V, MacLachlan C, Müller W, Prodhomme C (2017) Multi-model assessment of the impact of soil moisture initialization on mid-latitude summer predictability. Clim Dyn 49(11-12):3959-3974

Ardilouze C, Batté L, Déqué M, van Meijgaard E, van den Hurk B (2019a) Investigating the impact of soil moisture on European summer climate in ensemble numerical experiments. Clim Dyn 52(7-8):4011-4026

Ardilouze C, Batté L, Decharme B, Déqué M (2019b) On the link between summer dry bias over the US Great Plains and seasonal temperature prediction skill in a dynamical forecast system. Weather Forecast 34(4):1161-1172

Beck HE, Van Dijk AI, Levizzani V, Schellekens J, Gonzalez Miralles D, Martens B, De Roo A (2017) MSWEP: 3-hourly $0.25^{\circ}$ global gridded precipitation (1979-2015) by merging gauge, satellite, and reanalysis data. Hydrol Earth Syst Sci 21(1):589-615

Compo GP, Whitaker JS, Sardeshmukh PD, Matsui N, Allan RJ, Yin X, Gleason BE, Vose RS, Rutledge G, Bessemoulin P et al (2011) The twentieth century reanalysis project. Q J R Meteorol Soc 137(654):1-28

Fumière Q, Déqué M, Nuissier O, Somot S, Alias A, Caillaud C, Laurantin O, Seity Y (2019) Extreme rainfall in Mediterranean France during the fall: added value of the CNRM-AROME ConvectionPermitting Regional Climate Model. Climate Dynamics 1-15

Guillod BP, Orlowsky B, Miralles DG, Teuling AJ, Seneviratne SI (2015) Reconciling spatial and temporal soil moisture effects on afternoon rainfall. Nat Commun 6:6443

Helgert S, Khodayar S (2020) Improvement of the soil-atmosphere interactions and subsequent heavy precipitation modelling by enhanced initialization using remotely sensed $1 \mathrm{~km}$ soil moisture information. Remote Sens Environ 246:111812

Hersbach H, Bell B, Berrisford P, Hirahara S, Horányi A, MuñozSabater J, Nicolas J, Peubey C, Radu R, Schepers D et al (2020) The ERA5 global reanalysis. Q J R Meteorol Soc

Imamovic A, Schlemmer L, Schär C (2017) Collective impacts of orography and soil moisture on the soil moisture-precipitation feedback. Geophys Res Lett 44(22):11-682

Knist S, Goergen K, Buonomo E, Christensen OB, Colette A, Cardoso RM, Fealy R, Fernández J, García-Díez M, Jacob D et al (2017) Land-atmosphere coupling in EURO-CORDEX evaluation experiments. J Geophys Res Atmos 122(1):79-103

Koster RD, Dirmeyer PA, Guo Z, Bonan G, Chan E, Cox P, Gordon C, Kanae S, Kowalczyk E, Lawrence D et al (2004) Regions of strong coupling between soil moisture and precipitation. Science 305(5687):1138-1140

Koster RD, Schubert SD, DeAngelis AM, Molod AM, Mahanama SP (2020) Using a simple water balance framework to quantify the 
impact of soil moisture initialization on subseasonal evapotranspiration and air temperature forecasts. J Hydrometeorol

Koster RD, Sud Y, Guo Z, Dirmeyer PA, Bonan G, Oleson KW, Chan E, Verseghy D, Cox P, Davies H et al (2006) GLACE: the global land-atmosphere coupling experiment. Part I: overview. J Hydrometeorol 7(4):590-610

Lehmann P, Merlin O, Gentine P, Or D (2018) Soil texture effects on surface resistance to bare-soil evaporation. Geophys Res Lett 45(19):10-398

Lorenz R, Jaeger EB, Seneviratne SI (2010) Persistence of heat waves and its link to soil moisture memory. Geophys Res Lett 37(9)

Materia S, Ardilouze C, Prodhomme C, Donat MG, Benassi M, Doblas-Reyes FJ, Peano D, Caron LP, Ruggieri P, Gualdi S (Submitted), Summer temperature response to extreme spring soil water conditions in the Mediterranean transitional climate regime. Clim Dyn

Materia S, Borrelli A, Bellucci A, Alessandri A, Di Pietro P, Athanasiadis P, Navarra A, Gualdi S (2014) Impact of atmosphere and land surface initial conditions on seasonal forecasts of global surface temperature. J Clim 27:9253-9271

Orlowsky B, Seneviratne SI (2013) Elusive drought: uncertainty in observed trends and short-andlong-term CMIP5 projections. Hydrol Earth Syst Sci 17(5):1765-1781

Orth R, Dutra E, Pappenberger F (2016) Improving weather predictability by including land surface model parameter uncertainty. Mon Weather Rev 144(4):1551-1569

Orth R, Seneviratne SI (2017) Variability of soil moisture and sea surface temperatures similarly important for warm-season land climate in the Community Earth System Model. J Clim 30(6):2141-2162

Poli P, Hersbach H, Dee DP, Berrisford P, Simmons AJ, Vitart F, Laloyaux P, Tan DG, Peubey C, Thépaut J-N et al (2016) ERA20C: an atmospheric reanalysis of the twentieth century. J Clim 29(11):4083-4097

Rayner N, Parker DE, Horton E, Folland CK, Alexander LV, Rowell D, Kent E, Kaplan A (2003) Global analyses of sea surface temperature, sea ice, and night marine air temperature since the late nineteenth century. J Geophys Res Atmos 108(D14)

Sanna A, Borrelli A, Athanasiadis P, Materia S, Storto A, Navarra A, Tibaldi S, Gualdi S (2016) CMCC-SPS3: the CMCC Seasonal Prediction System 3. CMCC Research Paper RP0285

Santanello JA Jr, Dirmeyer PA, Ferguson CR, Findell KL, Tawfik AB, Berg A, Ek M, Gentine P, Guillod BP, van Heerwaarden C et al (2018) Land-atmosphere interactions: the LoCo perspective. Bull Am Meteorol Soc 99(6):1253-1272

Schneider U, Becker A, Finger P, Meyer-Christoffer A, Rudolf B, Ziese M (2018) GPCC Full Data Monthly Product Version 2018 at 1.0 : monthly land-surface precipitation from rain-gauges built on gtsbased and historic data. ftp://ftp.dwd.de/pub/data/gpcc/html/fulld ata-monthly_v2018_doi_download.html

Schneider U, Finger P, Meyer-Christoffer A, Rustemeier E, Ziese M, Becker A (2017) Evaluating the hydrological cycle over land using the newly-corrected precipitation climatology from the Global Precipitation Climatology Centre (GPCC). Atmosphere 8(3):52

Schär C, Lüthi D, Beyerle U, Heise E (1999) The soil-precipitation feedback: a process study with a regional climate model. J Clim 12(3):722-741

Seneviratne SI, Koster RD, Guo Z, Dirmeyer PA, Kowalczyk E, Lawrence D, Liu P, Mocko D, Lu C-H, Oleson KW et al (2006) Soil moisture memory in AGCM simulations: analysis of global landatmosphere coupling experiment (GLACE) data. J Hydrometeorol 7(5):1090-1112

Seneviratne SI, Wilhelm M, Stanelle T, van den Hurk B, Hagemann S, Berg A, Cheruy F, Higgins ME, Meier A, Brovkin V et al (2013) Impact of soil moisture-climate feedbacks on CMIP5 projections: first results from the GLACE-CMIP5 experiment. Geophys Res Lett 40(19):5212-5217

Taylor CM, de Jeu RA, Guichard F, Harris PP, Dorigo WA (2012) Afternoon rain more likely over drier soils. Nature 489(7416):423-426

Tuttle SE, Salvucci GD (2017) Confounding factors in determining causal soil moisture-precipitation feedback. Water Resour Res 53(7):5531-5544

Tuttle S, Salvucci G (2016) Empirical evidence of contrasting soil moisture-precipitation feedbacks across the United States. Science 352(6287):825-828

Van den Hurk B, Kim H, Krinner G, Seneviratne SI, Derksen C, Oki T, Douville H, Colin J, Ducharne A, Cheruy F et al (2016) LS3MIP (v1. 0) contribution to CMIP6: the land surface, snow and soil moisture model intercomparison project-aims, setup and expected outcome. Geosci Model Dev 9:2809-2832

Voldoire A, Saint-Martin D, Sénési S, Decharme B, Alias A, Chevallier M, Colin J, Guérémy J-F, Michou M, Moine M-P, Nabat P, Roehrig R, Salas y Mélia D, Séférian R, Valcke S, Beau I, Belamari S, Berthet S, Cassou C, Cattiaux J, Deshayes J, Douville H. H, Franchisteguy L, Ethé C, Geoffroy O, Lévy C, Madec G, Meurdesoif Y, Msadek R, Ribes A, Sanchez E, Terray L, Waldman R (2019) Evaluation of CMIP6 DECK experiments with CNRM-CM6-1. Journal of Advances in Modeling Earth Systems http://www.umr-cnrm.fr/cmip6/references

Wei J, Dirmeyer PA (2012) Dissecting soil moisture-precipitation coupling. Geophys Res Lett 39(19)

Yang K, Wang C, Bao H (2016) Contribution of soil moisture variability to summer precipitation in the Northern Hemisphere. J Geophys Res Atmos 121(20):12-108

Yang Y, Donohue RJ, McVicar TR (2016) Global estimation of effective plant rooting depth: Implications for hydrological modeling. Water Resour Res 52(10):8260-8276

Publisher's Note Springer Nature remains neutral with regard to jurisdictional claims in published maps and institutional affiliations. 